\title{
THE POSSIBILITY OF USING PSEUDO-PHASE SPACE METHODS IN THE ANALYSIS OF THE POSITIVE DISPLACEMENT PUMP WEAR
}

\begin{abstract}
SUMMARY
In this paper the possibility of tracking the evolution of reconstructed pseudo-phase portraits in the diagnosis of positive-displacement pump wear has been presented. The reconstructed pseudo-phase portraits were obtained from vibration signals measured in characteristic places on the pump casing and from the dynamic pressure graphs recorded in the output port of the pump during the passive test experiment. The recorded measurement concerned to tree state of pump condition: in full working order, in part working order and pump with wear out elements.
\end{abstract}

Keywords: positive-displacement pump, mutual information, pseudo-phase space method, diagnostic of machines

\section{MOŻLIWOŚĆ WYKORZYSTANIA METODY PSEUDOPRZESTRZENI FAZOWEJ W ANALIZIE ZUŻYCIA ELEMENTÓW POMPY WYPOROWEJ}

W artykule przedstawiono możliwość wykorzystania odtworzonych z zarejestrowanych sygnałów przebiegów pseudoportretów fazowych $w$ diagnostyce zużycia pomp wyporowych na przykładzie badań pompy wielotłoczkowej. Odtworzone pseudoportrety fazowe otrzymano w wyniku przeprowadzenia biernego eksperymentu diagnostycznego, ze zmierzonych w charakterystycznych miejscach korpusu pompy sygnałów wibracji oraz dodatkowo z przebiegów ciśnienia dynamicznego dla trzech stanów pracy pompy: petnej sprawności, stanu cześsciowej sprawności oraz pracy pompy zużytej.

Slowa kluczowe: pompa wyporowa, informacja wzajemna, metoda pseudoprzestrzeni fazowej, diagnostyka maszyn

\section{INTRODUCTION}

The main task of the positive displacement pump in hydrostatic drive and control systems is to convert input mechanical energy into hydrostatic energy of the working medium in its pumping port. The positive displacement pump produces a specific volume of the working medium from the suction space to the pumping space (with a tight separation of these spaces from each other) by means of the positive displacement assembly (Stryczek 1995).

Positive displacement pumps are subject to regular wear, which affects their performance parameters. As a result of physical wear, a gradual expansion of the clearances between the working elements of pumps takes place, leading to an increase in volumetric losses. With some degree of wear, there may be problems with maintaining the required flow and pressure. Simultaneously with the progressive wear, there is an increase in vibration and noise, and also a change in the pump's thermal state. In axial piston pumps, excessive clearances doesn't prevent stable piston movement, leading at one point to the blockage of the pump mechanism. Abrupt stopping of the pump's operation can have serious consequences for both the hydraulic system powered and equipment in which the system is installed.

Operation of the positive displacement pump as a mechanical assembly consisting of many components with linear and nonlinear dynamics generates measurable diagnostic signals, many of which have their nonlinear source. The beginning of damage to the pump component causes the occurrence in the measurable signal (e.g. vibration signal) of synchronous components as well as a number of quasiperiodic and chaotic components. Considering the measuring signal obtained from the test object, and assuming that its source is in the linear system, in its analysis, we can use classical methods of time-frequency signal analysis (i.e. correlation and autocorrelation functions, short-time Fourier transform or wavelet analysis) (Stojek and Kowal 2011), or after the assumption that the measured signal comes from a system with nonlinear dynamics, we can use in its analysis one of the methods used in the study of deterministic chaos of machines (Hilborn 1994, Kranz and Schreiber 1997, Moon 2004), for example, using the pseudo-phase plane method.

The article presents the possibility of tracking the evolution of reconstructed pseudo-phase portraits (based on recorded signal graph) in the diagnosis of positive-displacement pump wear. The reconstructed pseudo-phase portraits were obtained from vibration signals measured in characteristic places in the pump body, plus from the dynamic pressure graphs recorded in its output port during the test experiment.

\section{DESCRIPTION OF THE TEST OBJECT AND OPERATIONAL DAMAGE TO ITS MAIN COMPONENTS}

The test object was an axial multi-piston pump WPTO2-10, whose structural diagram is presented in Figure 1. The rotor (2) with the assembly of seven pistons (4) and a supporting cylindrical bearing (8a) are mounted coaxially on the drive shaft (1) supported on two ball bearings (8b), (8c). 


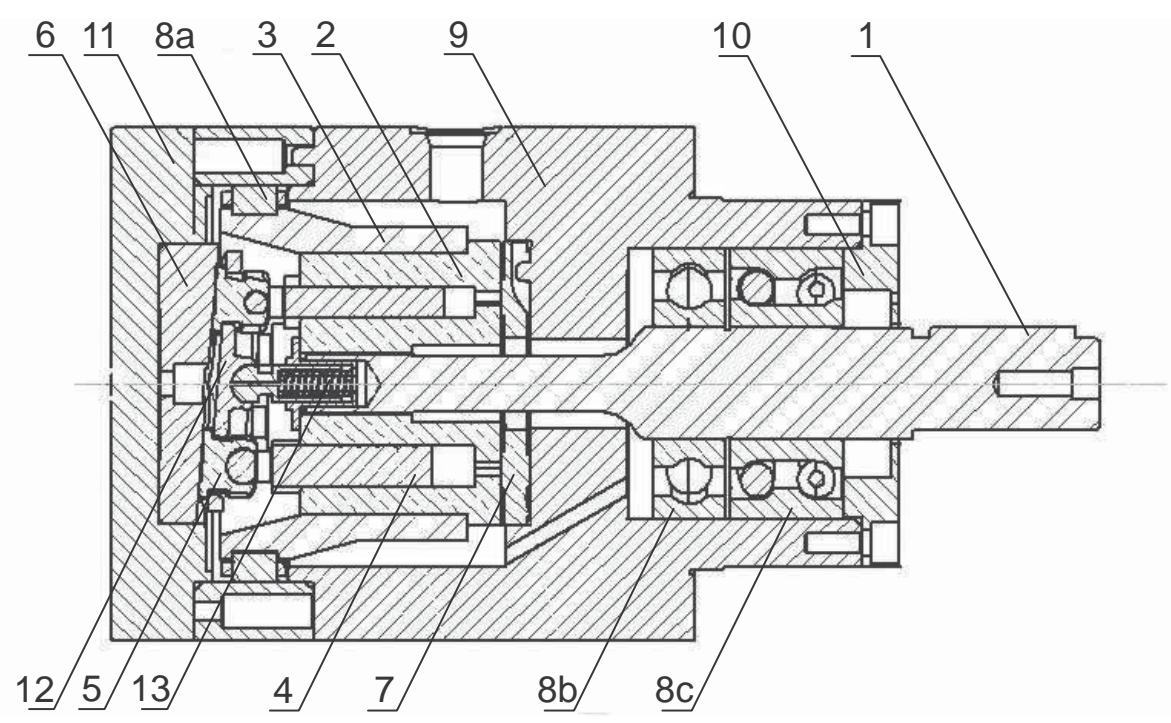

Fig. 1. Structural diagram of the WPTO2-10 axial multi-piston swash-plate pump: 1 - shaft; 2 - rotor; 3 - rotor housing; 4 - piston, 5 - shoe; 6 - swash plate; 7 - valve-port plate; $8 \mathrm{a}$ - cylindrical bearing; $8 \mathrm{~b}, 8 \mathrm{c}$ - ball bearings; 9 - body; 10 - back lid; 11 - front lid; 12 - retaining ring; 13 - compression spring (Stojek and Łatas 2011)

The pistons (4) with the rotor (2) perform a rotational movement and their shoe (5), sliding over the surface of the stationary swash plate (6), force an additional progressive-turning movement in the cylinders of the rotor, responsible for pumping the medium. In addition, the rotor (2) slides on the stationary valve-port plate (7), in which the pump's suction and pumping holes are made.

Wear of the elements of multi-piston positive displacement pumps is determined by the forces which occur during cooperation of its elements forming the kinematic pairs (e.g. piston - cylinder, valve-port plate-rotor, piston shoe-swash plate) and unsuitable operating conditions of pumps, such as crossing the nominal working pressure, low viscosity of the working medium and its insufficient filtration. The most common type of wear of positive displacement pump elements is their abrasive wear. The wear of this type occurs in all parts of the pump, between which there is relative motion and contact. In the analysed multi-piston pump construction, this is especially the case with (Stojek and Kowal 2011, Stojek and Latas 2011):

- the surface of the swash plate and the piston shoe sliding on its surface,

- in kinematic pairs: piston-cylinder,

- at the interface between the valve-port plate and the front surface of the rotor.

The wear of the swash plate in the multi-piston pump consists of the deepening of an elliptical cavity (Fig. 2) on its surface, due to loss of hydrostatic support between the surface of the plate and the piston shoe sliding on it.

The wear of the valve-port plate (related to its abrasive wear) is the result, among other things, of the loss of the lubricant layer between the surface of the plate and the front surface of the rotor, which leads to the emergence of drainage micro-channels on the so-called plate bridge plane (Fig. 3).

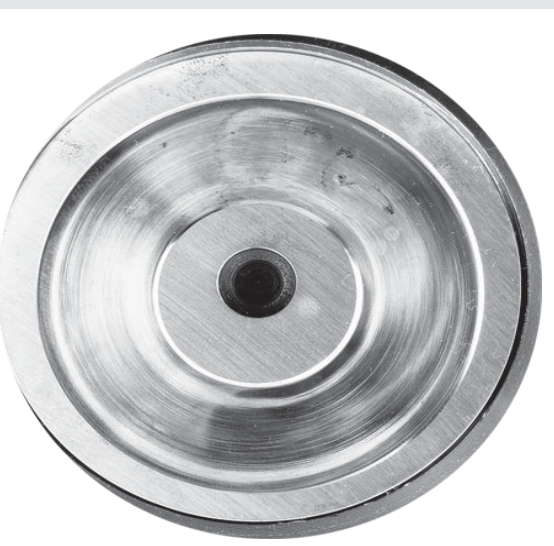

Fig. 2. The view of swash plate surface condition for out of order surface plate

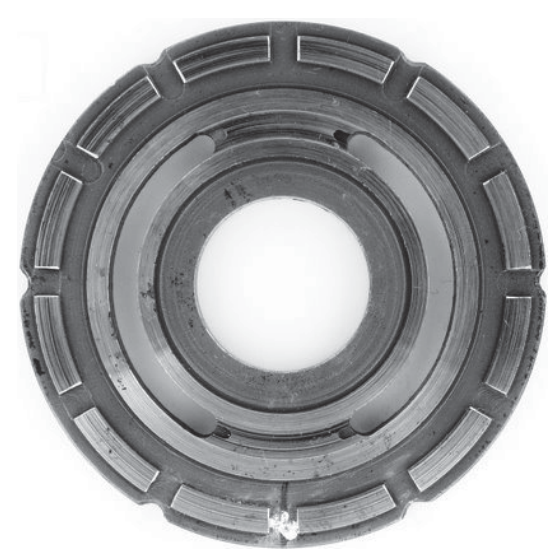

Fig. 3. The view of valve-plate with magnified wear zone

Wear of the rotor (Fig. 4) is mainly due to the forces present on the surfaces of the piston-cylinder kinematic pairs. These forces result from the load on the piston of normal 
force equal to the radial component of the reaction of the swash plate to the piston shoe and rotor's inertia force in a rotation with assumed angular velocity $\omega$ (Stojek and Łatas 2011, Stryczek 1995). Excessive load on the rotor leads, among other things, to the abrasive wear of its components and increase in radial clearance in piston-cylinder pairs. This results in increased volumetric losses and lowering overall pump efficiency (Stojek and Łatas 2011).

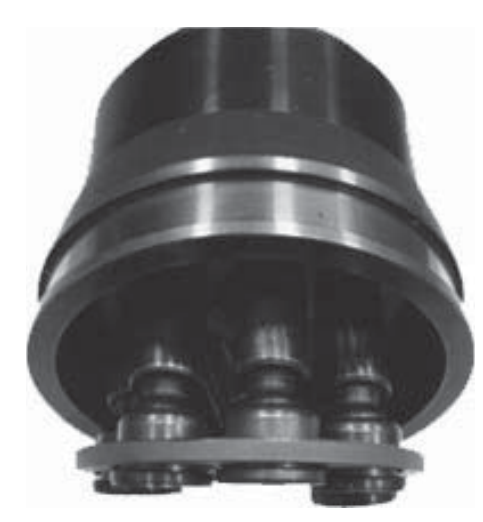

Fig. 4. The view of pump's rotor unit

During the course of the several hour long passive test experiment (Cempel 1992, Stojek and Kowal 2011), the pump had been working using contaminated working medium under the load of constant static pressure, whose value did not exceed the nominal pressure of the pump. The basic operational parameters of the pump (static pressure, dynamic pressure, flow, speed) were measured, as well as the additionally generated residual processes (oil temperature and vibrations at characteristic points of the body of the pump). The recorded graphs were subjected to time-frequency analysis and pseudo-phase plane analysis (Stojek and Kowal 2011).

\section{THE PSEUDO-PHASE PLANE METHOD}

The pseudo-phase space method (Hilborn 1994, Kanz and Schreiber 1997, Moon 2004) used in the analysis of the dynamics of the positive displacement pump is one of many methods used to analyse the phenomena of deterministic chaos in mechanical objects. It consists of reconstructing the dynamics of the object in the space of states relying on the time series representing the measured signal.

The basic assumption in the use of this method (for the analysis of the measured $X(t)$ signal) is to assume that the space where the evolution of the analysed object dynamics is not described in a one-dimensional plane of possible time series values but the evolution of the system dynamics occurs in the space of higher dimension $\underline{X}(t)$ vectors. The transition to this space is achieved using so-called embedding theorem of the measured time series (Awrejcewicz 1994, Cao 1997).

This theorem states that a series of scalar measurements $X(t)$ can be used in order to define the orbits describing the evolution of the states of the system in $m$-dimensional Eu- clidean space. The orbits will then consist of points $\underline{X}(t)$ with coordinates:

$$
\underline{X}(t)=[X(t), X(t+\tau), \ldots X(t+(m-1) \tau)]
$$

where:

$\tau$ - time delay,

$m$ - embedding dimension.

Geometrically the entire set of these points forms a pattern called an attractor in the $m$-dimensional phase space. According to literature (Cao 1997, Hilborn 1994, Moon 2004) the dimension of embedding $m$ must be greater than or equal to $2 \cdot d+1$ in order to reconstruct $d$ dimensional system.

In practice usually one does not know the real $d$ - dimension of the dynamic system and the $m$ embedding dimension which is significant for the phase space reconstruction. To estimate the value of embedding dimension $m$ one can use several methods (e.g. the singular value decomposition method, a method which computes some invariant on the attractor or the method of false neighbours) and their modifications (Cao 1997, Kranz and Schreiber 1997, Moon 2004). In this paper the false nearest neighbour (FNN) algorithm is used to estimate the best value of the embedding dimension $m$ (Cao 1997).

Mathematically the FNN algorithm states that each point $X(i)$ in the time series looks for its nearest neighbour $X(j)$ in an $m$-dimensional space. The algorithm calculates the distance between $|X(i)-X(j)|$, then iterates both points and computes (Cao 1997):

$$
R(i, m)=\frac{\|X(i, m+1)-X(j, m+1)\|}{\|X(i, m)-X(j, m)\|}
$$

In the next step the computed value of $R(i, m)$ is compared to assumed threshold value $R(t)$. If $R(i, m) \geq R(t)$ it states that point has a false nearest neighbour.

During the phase portraits reconstruction the quality of them (pseudo-phase portraits) depends largely on the size of the adopted delay $\tau$. If the adopted value of the delay is too small, then in the case of the time series carrying useful information as well as noise, the difference between time vectors $\underline{X}(1)$ and $\underline{\boldsymbol{X}}(2)$ will be insignificant, and the resulting trajectory will be a straight line $X(i)=X(i+1)$. To avoid this, the value of the applied delay $\tau$ should ensure fulfilling the assumption of independence of the variables $X(i), X(i+1)$ (Fraser and Swinney 1986). A natural way to determine the delay $\tau$, which ensures the linear independence of variables, is the adoption of such a value at which the autocorrelation function of the measured time series for the first time takes the value zero. Another more effective way to estimate the delay $\tau$ is the calculation of the first minimum of the averaged mutual information $I W$ graph of the time series (Fraser and Swinney 1986). Mutual information, in contrast to the autocorrelation function, (which only checks linear dependence between the variables under consideration) in a comprehensive way measures the dependence between two variables and therefore is a better selection criterion for the value of delay $\tau$ sought. 
The general form of the expression describing the value of the averaged mutual $I W$ obtained from discrete time series is expressed using the formula [4]:

$$
\begin{aligned}
& I W(\tau)=\sum_{X(i), X(i+\tau)} P(X(i), X(i+\tau)) \times \\
& \times \log _{2}\left[\frac{P(X(i), X(i+\tau))}{P(X(i)) P(X(i+\tau))}\right]
\end{aligned}
$$

where:

$$
\begin{aligned}
& P(X(i)), P(X(i+\tau)) \text { - individual probabilities for the } \\
& P(X(i), X(i+\tau)) \text { - the joint probability density for }
\end{aligned}
$$

In the tests carried out by the author, the value of delay $\tau$, at which the first local minimum of the averaged mutual information $I W$ graph occurred was adopted as optimal for the construction of reconstructed phase portraits.

\section{TEST RESULTS}

The experiments carried out required among other things to record the vibration acceleration signals in the characteristic pump casing locations (i.e. swash plate, valve-port plate and rotor) and dynamic pressure graphs in its pumping port.

At the beginning of the experiments it was assumed that the wear of the tested pump will be assessed in a qualitative way by using the reconstructed phase portraits received from the time series, obtained for the calculated delay $\tau$.

Changes in the pseudo-phase plane portraits of the test pump due to progressive wear of its components (determined for the vibration acceleration graphs) are summarised in Figures from 5 to 8 . In addition, the Figure 9 summarise the forms of the reconstructed phase portraits obtained from the measurements of dynamic pressure in the pump's output port.

Discrete values of time delay samples at which the averaged mutual information $I W$ graphs reached their first minimum together with estimated earlier values of embedding dimension $m$ for which the reconstructed phase planes were obtained, are presented in Tables 1 to 4 .

Table 1

\begin{tabular}{|l|c|c|c|c|}
\hline \multicolumn{1}{|c|}{ Vibration measurement on swash plate $-X$ axis } & Inspection No. 1 & Inspection No. 2 & Inspection No. 3 & Inspection No. 4 \\
\hline Lag samples of first $I W$ minimum $[-]$ & 18 & 15 & 16 & 19 \\
\hline Embedded dimension $m$ & 10 & 10 & 7 & 5 \\
\hline
\end{tabular}

a)

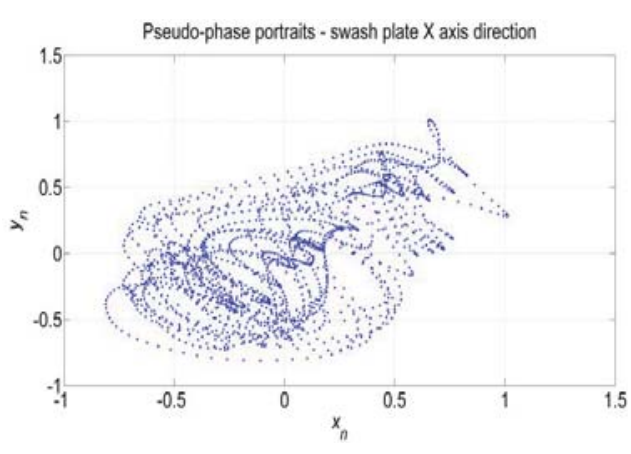

c)

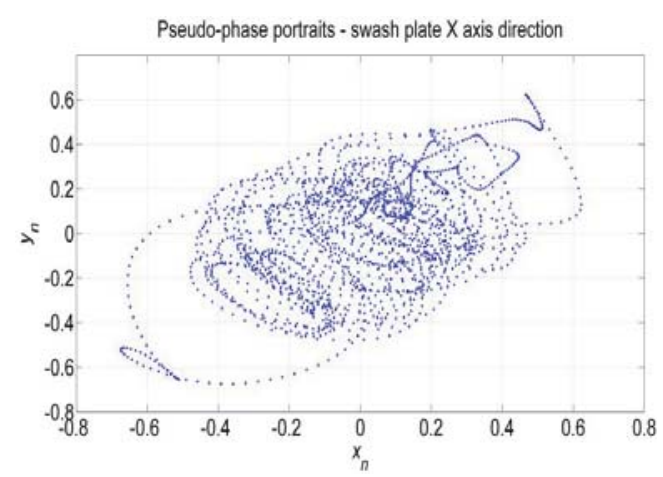

b)

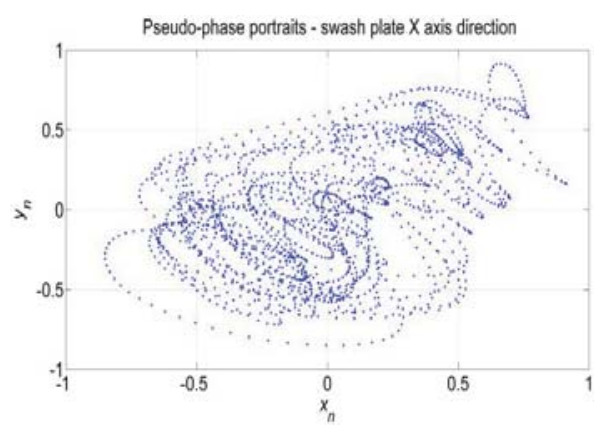

d)

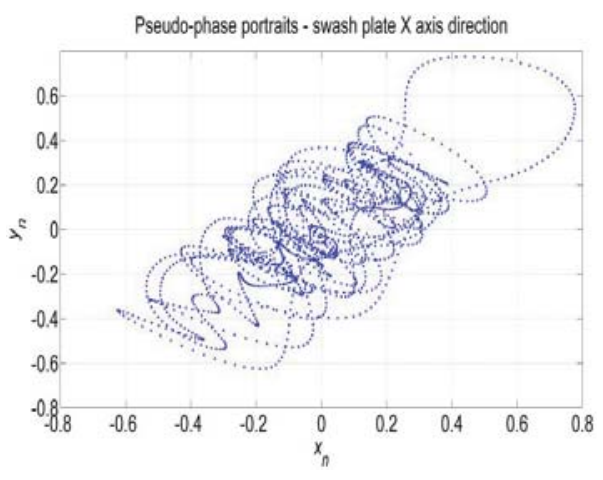

Fig. 5. Pseudo-phase portraits gained from the vibration measurement on the swash plate in the $X$ direction: a) beginning of the experiment - efficient pump; b), c) transient period; d) the end of the experiment - worn out pump 
a)

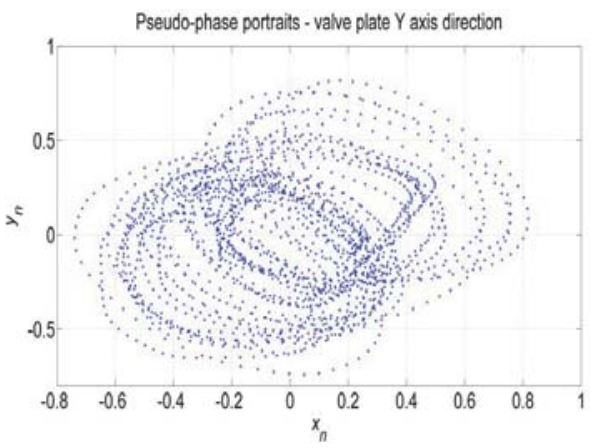

c)

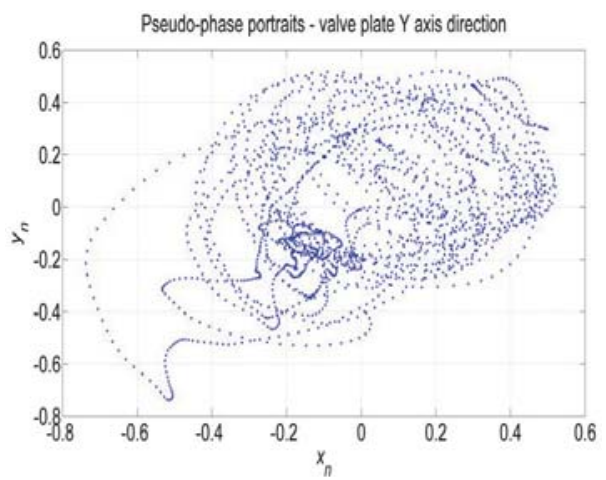

b)

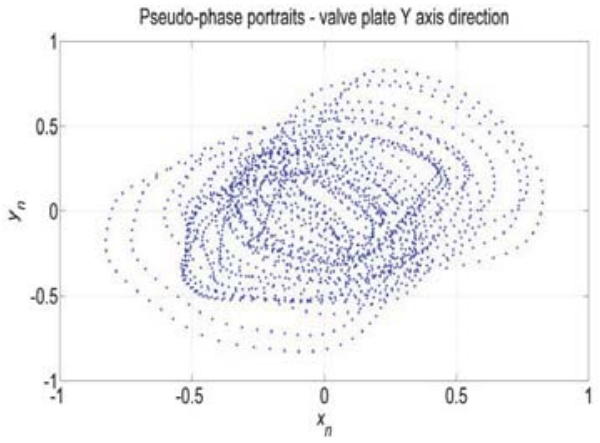

d)

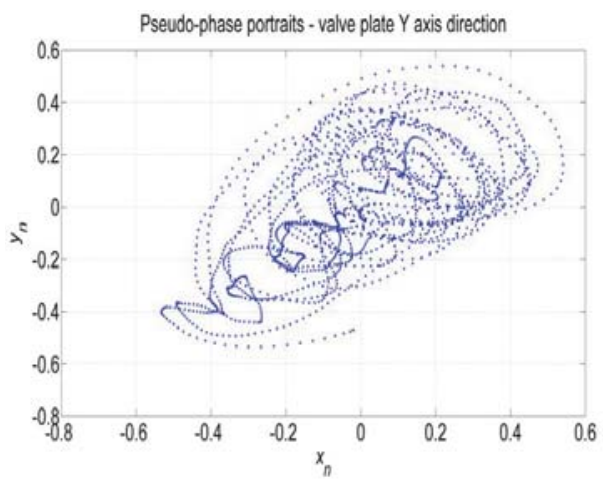

Fig. 6. Pseudo-phase portraits gained from the vibration measurement on the valve plate in the $Y$ direction: a) beginning of the experiment - efficient pump; b), c) transient period; d) the end of the experiment - worn out pump

a)

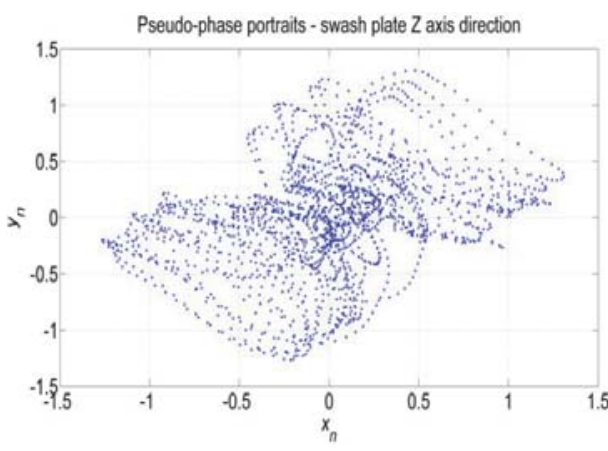

c)

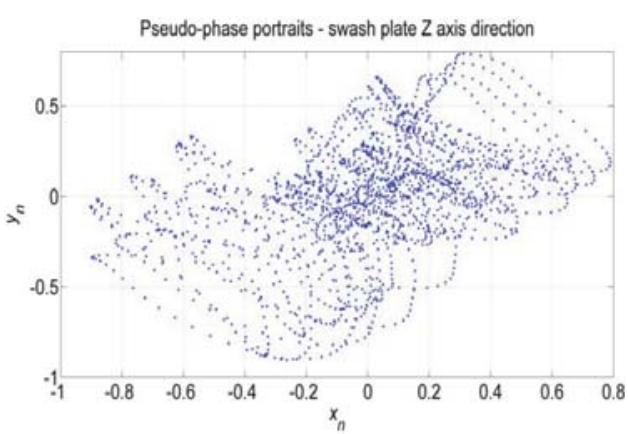

b)

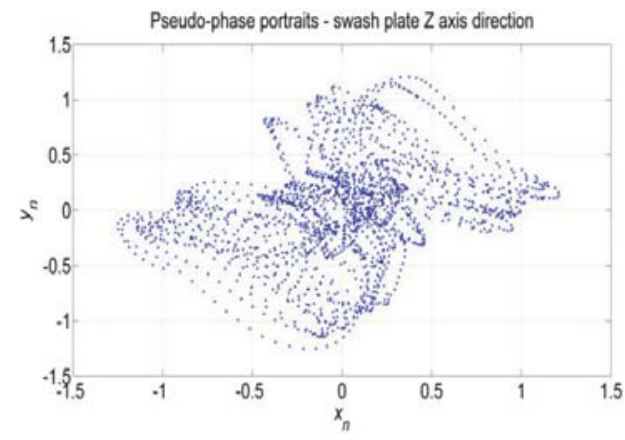

d)

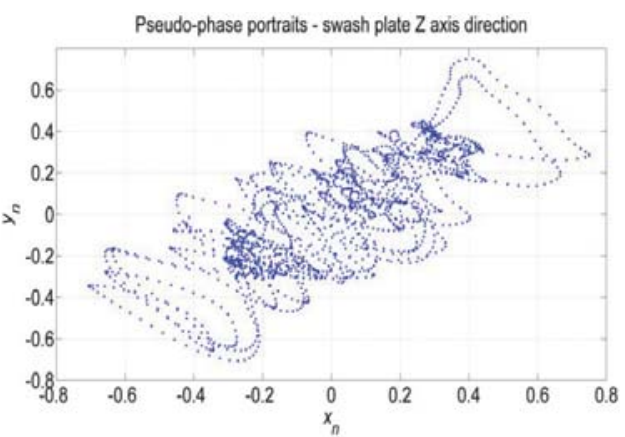

Fig. 7. Pseudo-phase portraits gained from the vibration measurement on the swash plate in the $Z$ direction: a) beginning of the experiment - efficient pump; b), c) transient period; d) the end of the experiment - worn out pump 
a)

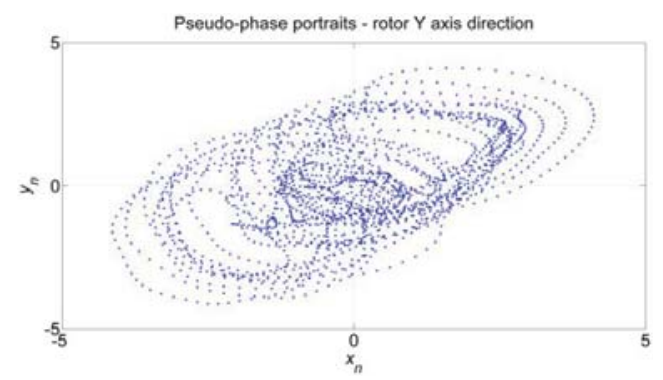

c)

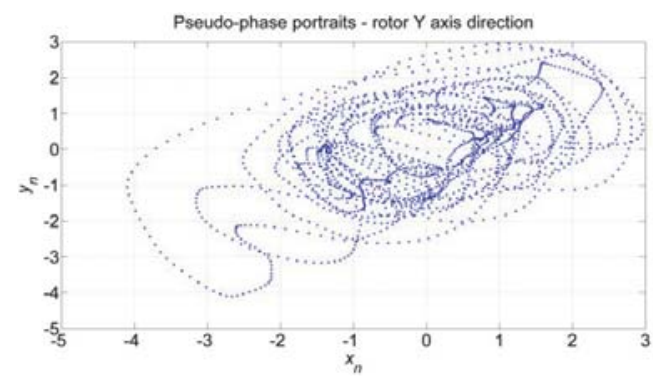

b)

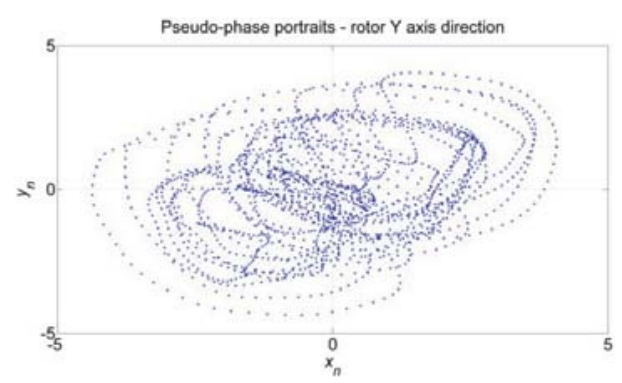

d)

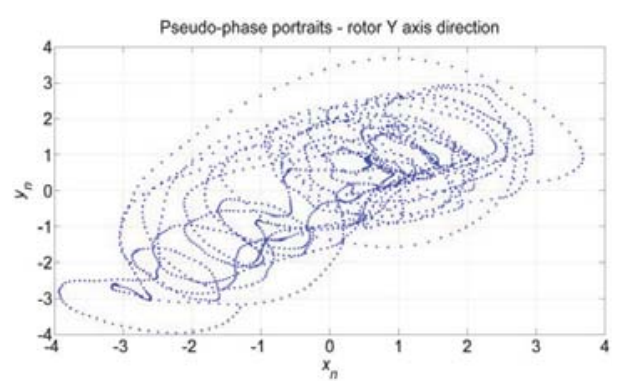

Fig. 8. Pseudo-phase portraits gained from the vibration measurement on the rotor in the $Y$ direction: a) beginning of the experiment - efficient pump; b), c) transient period; d) the end of the experiment - worn out pump

a)

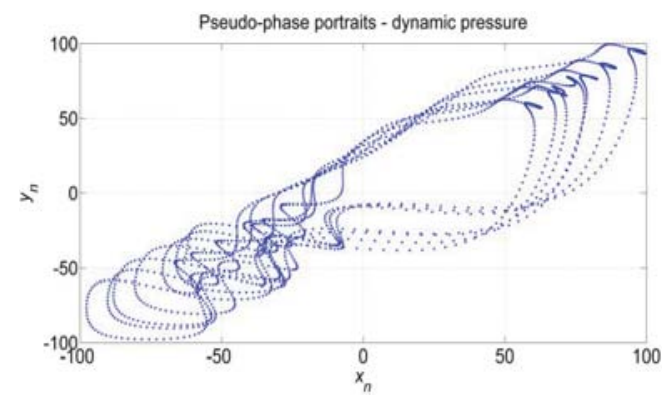

c)

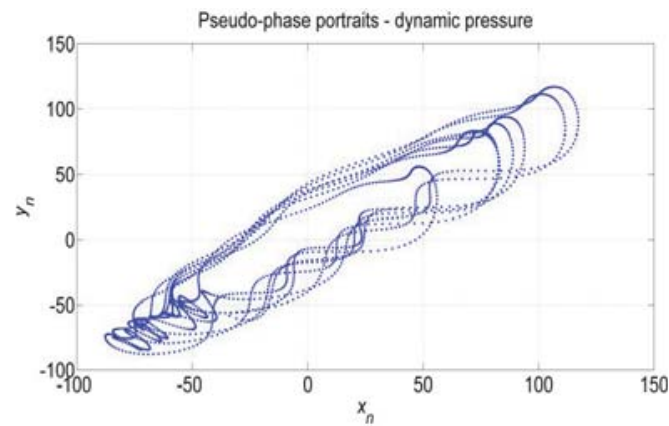

b)

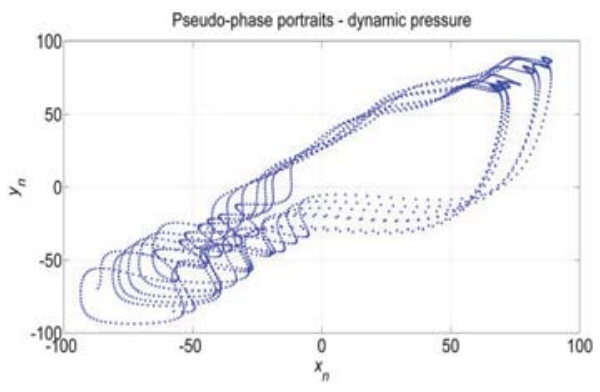

d)

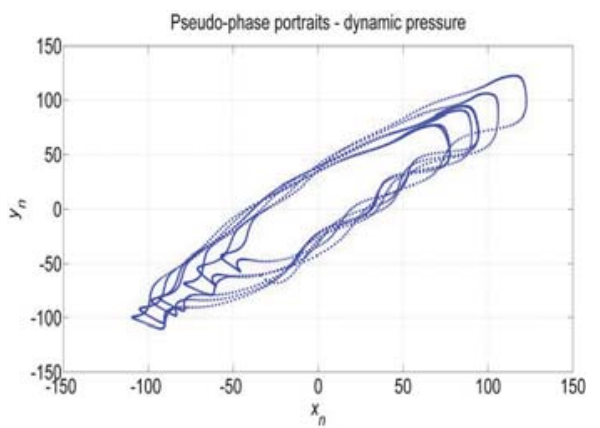

Fig. 9. Pseudo-phase portraits gained from the dynamic pressure measurement in out port of the pump: a) beginning of the experiment - efficient pump; b), c) transient period; d) the end of the experiment - worn out pump

Table 2

\begin{tabular}{|l|c|c|c|c|}
\hline \multicolumn{1}{|c|}{ Vibration measurement on valve plate $-Y$ axis } & Inspection No. 1 & Inspection No. 2 & Inspection No. 3 & Inspection No. 4 \\
\hline Lag samples of first $I W$ minimum $[-]$ & 14 & 12 & 14 & 15 \\
\hline Embedded dimension $m$ & 7 & 6 & 7 & 9 \\
\hline
\end{tabular}


Table 3

\begin{tabular}{|l|c|c|c|c|}
\hline \multicolumn{1}{|c|}{ Vibration measurement on swash plate $-Z$ axis } & Inspection No. 1 & Inspection No. 2 & Inspection No. 3 & Inspection No. 4 \\
\hline Lag samples of first $I W$ minimum $[-]$ & 18 & 18 & 18 & 19 \\
\hline Embedded dimension $m$ & 6 & 6 & 8 & 8 \\
\hline
\end{tabular}

Table 4

\begin{tabular}{|l|c|c|c|c|}
\hline \multicolumn{1}{|c|}{ Dynamic pressure measurement } & Inspection No. 1 & Inspection No. 2 & Inspection No. 3 & Inspection No. 4 \\
\hline Lag samples of first $I W$ minimum [-] & 16 & 19 & 17 & 17 \\
\hline Embedded dimension $m$ & 7 & 7 & 6 & 7 \\
\hline
\end{tabular}

Table 5

\begin{tabular}{|l|c|c|c|c|}
\hline \multicolumn{1}{|c|}{ Vibration measurement on swash plate $-X$ axis } & Inspection No. 1 & Inspection No. 2 & Inspection No. 3 & Inspection No. 4 \\
\hline Lag samples of first $I W$ minimum $[-]$ & 17 & 18 & 18 & 18 \\
\hline Embedded dimension $m$ & 5 & 6 & 10 & 15 \\
\hline
\end{tabular}

\section{QUANTITATIVE MEASURE OF PSEUDO-PHASE PORTRAITS}

There are many qualitative measures from the non-linear dynamic analysis which can be adopted to measure the dimension of the pseudo-phase portraits (e.g.: pointwise dimension, entropy information and correlation dimension) (Hilborn 1994, Moon 2004). One of the most popular forms of the measure of the attractor dimension is correlation dimension $d_{c}$ (Awrejcewicz 1994, Moon 2004).

In order to determine correlation dimension $d_{c}$, the obtained pseudo-phase portraits have to be discretized to a set of $N$ points $\left\{\mathrm{x}_{\mathrm{i}}\right\}$. Next the distance between pair of points has been calculated $\left(\mathrm{s}_{k j}=\left|\mathrm{x}_{\mathrm{k}}-\mathrm{x}_{\mathrm{j}}\right|\right)$. Then the correlation function is defined as (Fraser and Swinney 1986):

$$
C(r)=\frac{\lim _{N \rightarrow \infty} 1}{N^{2}}\left(\begin{array}{c}
\text { number of pairs }(k, j) \\
\text { with distance } \mathrm{s}_{k j}<r
\end{array}\right)
$$

The more efficient way to calculate the correlation dimension is to consider the cumulative correlation $C(r)$ function defined as (Cao 1997, Moon 2004):

$$
C(r)=\frac{\lim _{N \rightarrow \infty} 1}{N^{2}} \theta(r-\|X(k)-X(j)\|)
$$

where:

$r$ - finite scale length,

$\theta-$ the Heaviside function,

$$
\begin{array}{r}
\|X(k)-X(j)\|=\sqrt{\sum_{i=1}^{m}\left(X_{k+(i-1) \tau}-X_{j+(i-1) \tau}\right)^{2}} \\
- \text { the Euclidean norm. }
\end{array}
$$

It has been found that function $C(r)$ exhibits dependence on $r$ as $r \rightarrow 0$ :

$$
\lim _{r \rightarrow 0} C(r)=a r^{d}
$$

The correlation dimension is then received as the slope of the $\ln C$ versus $\ln r$ curve:

$$
d_{c}=\lim _{r \rightarrow 0} \frac{\ln C(r)}{\ln r}
$$

The values of correlation dimensions $d_{c}$ calculated from the obtained pseudo-phase portraits (Figures from 5 to 9 ) were put together in Table 6.

Table 6

\begin{tabular}{|l|c|c|c|c|c|}
\cline { 2 - 6 } \multicolumn{1}{c|}{} & \multicolumn{5}{c|}{ Correlation dimension $d_{c}$ estimated from measured signal } \\
\hline $\begin{array}{c}\text { Condition } \\
\text { of pump }\end{array}$ & $\begin{array}{c}\text { Vib. on Swash } \\
\text { plate in } X \\
\text { direction }\end{array}$ & $\begin{array}{c}\text { Vib. on Swash } \\
\text { plate in } Z \text { direction }\end{array}$ & $\begin{array}{c}\text { Vib. on Valve } \\
\text { plate in } Y \text { direction }\end{array}$ & $\begin{array}{c}\text { Vib. on Rotor } \\
\text { in } Y \text { direction }\end{array}$ & Dynamic pressure \\
\hline Efficient pump & 1.872 & 1.895 & 1.962 & 1.922 & 1.698 \\
\hline Transient period & 1.855 & 1.863 & 1.919 & 1.883 & 1.860 \\
\hline Transient period & 1.918 & 1.88 & 1.918 & 1.878 & 1.819 \\
\hline Worn out pump & 1.896 & 1.822 & 1.922 & 1.853 & 1.819 \\
\hline
\end{tabular}




\section{TESTS RESULTS}

Immediately after the passive test experiment finished, the types of damage occurring to the components of the multi-piston pump were analysed. Wear of the valve-port plate and the pump rotor has been identified, and the nature of the damage of the elements corresponded to their descriptions appearing at the beginning of the article. There was no wear to the surface of the swash plate, which is explained by the existence of hydrostatic support between cooperating elements in the kinematic pair. This support for the entire duration of the experiment ensured the presence of smooth friction on the surfaces of interacting elements.

Analysing the reconstructed pseudo-phase portraits, it can be concluded that their shape evolves with the progressive wear of pump components, gradually moving from ordered to unordered structure. Change of the shape of the pseudo-phase portrait is accompanied by a change of the plane which it applies to. A reduction of this plane with the progressive wear of the pump elements is observed. The phenomena described above apply only to portraits reconstructed from the vibration runs on the pump housing.
Considering the pseudo-phase portraits obtained from the measurements of the dynamic pressure in the pump's output pipe, it should be noted that the progressive wear of the pump leading to its failure is revealed in the gradual unfolding of the pseudo-phase plane, which at the end of the experiment takes the shape similar to an ellipse. The reduction (or increase) of the area covered by the pseudo-phase portrait with the increase in the wear of the pump is not observed in this case.

A compression of correlation dimensions $d_{c}$ values as the quantitative measure of pseudo-phase portraits was shown in Figure 10. It can be found that for $d_{c}$ values estimate for vibration measurements in $\mathrm{Y}$ and $\mathrm{Z}$ direction on pumps casing near: rotor, valve plate and swash plate the $d_{c}$ values have a tendency to decrease with the pump wear.

In the case when $d_{\mathrm{c}}$ values were calculated from vibration measurements in the $\mathrm{X}$ direction near the swash plate and from measurements of dynamic pressure in the pump's output pipe the change in the runs of the correlation dimension values doesn't form a clear tendency with progressive wear of the pump.

Additionally, the comparison of emending dimensions $m$ change as a function of the pump's condition is presented in Figure 11.

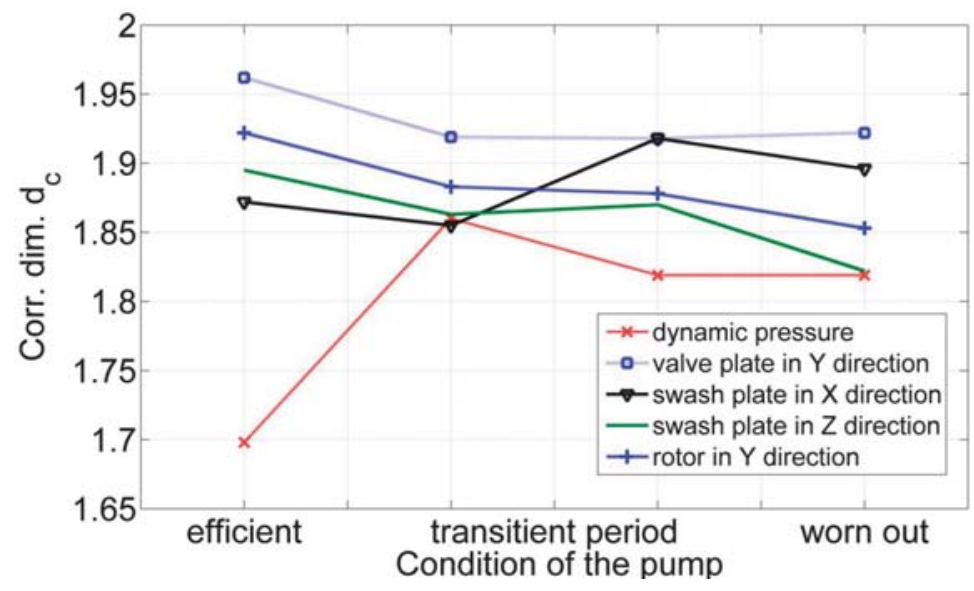

Fig. 10. Comparison of correlation dimension $d_{c}$ runs estimated from the vibration measurements as a function of the pump's wear

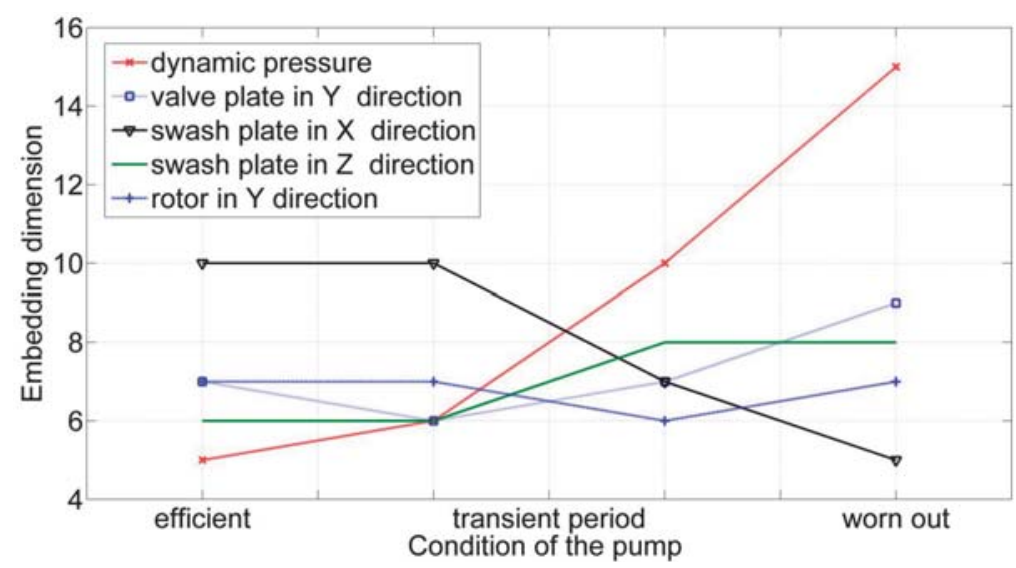

Fig. 11. Comparison of embedding dimension $m$ runs estimated from the vibration measurements as a function of the pump's wear 
From figure 11 one can find that when the pump's elements begin to wear out, the embedded dimension $m$ estimated from the vibration time series measured in $\mathrm{Z}$ direction near valve plate and the swash plate have a tendency to increase. The run of embedded dimensions calculated from the dynamic pressure series has the same trend. The opposite characteristic presents the embedded dimension estimated from the time series measured in $\mathrm{X}$ direction on the swash plate which has a tendency to decrease as the pump is wearing out. In the case of embedding dimension calculated from the vibration measurements near the pump's rotor the run doesn't form a clear tendency with progressive wear of the pump.

\section{SUMMARY AND CONCLUSIONS}

In the diagnosis of complex mechanical devices such as positive displacement pumps it is especially important to have useful sources of information on the examined object. Presented in this article changes of pseudo-phase portraits which evolve with the progressive wear of the pump in author's opinion can be a useful tool in his further diagnosis. The introduction of the quantitative measure of pseudo- phase portraits such as correlation dimensions $d_{c}$ values helps to observe trends in phase portraits change. Noticeable on some runs of the correlation dimensions values uncertainties (which make information of the pumps wear sometimes difficult) may be caused by additive noise in the measured signal.

In summary it should be stated that additional experiments with axial piston pumps and other types of positive displacement pumps (e.g. gear pumps, vane pumps or screw pumps) have to be carried out in order to assess the usefulness of pseudo-phase portraits in the analysis of the positive displacement pump wear. An analysis of pseudo-phase portraits gained from other types of positive displacement pumps with the selection of a proper method for noise reduction in the measure signals will be the subject of the author's future research work.

\section{References}

Awrejcewicz J. 1994, Dynamika nieliniowa maszyn, Wydawnictwo Politechniki Łódzkiej.

Cao L.1997, Practical method for determing the minimum embedding dimension of a scalar time series, Physica D, No. 110.

Cempel C. 1992, Diagnostyka maszyn, Wyd. Międzyresortowe Centrum Naukowe, Radom.

Fraser A.M., Swinney H.L.1986, Independent coordinates for strange attractors from mutual information, Phys. Rev. A 33, 1134-1140.

Grassberger P., Prcaccia I. 1983, Characterization of strange attractors, Physical Review Letters, No. 50.

Hilborn R.C. 1994, Chaos and Nonlinear Dynamics, Oxford University Press.

Kanz H., Schreiber T. 1997, Nonlinear time series analysis, Cambridge University Press.

Kudrewicz J. 2007, Fraktale $i$ chaos, WNT.

Moon F. C. 2004, Chaotic Vibrations, Wiley.

Stojek J, Kowal J. 2011, Ocena stanu zużycia pompy tłokowej osiowej przy иżсіu nieparametrycznych metod analizy sygnału, Przegląd Mechaniczny, r. LXX, z. 1, pp. 26-33.

Stojek J., Łatas W., 2011, A dynamic model of axial piston swash-plate pump for elements wear diagnosis, The Archive of Mechanical Engineering, vol. 2.

Stryczek S.1995, Napęd hydrostatyczny, Wydawnictwo Naukowo Techniczne, Warszawa.

Zieliński T. 2009, Od teorii do cyfrowego przetwarzania sygnałów, Wydawnictwo Komunikacji i Łączności, Warszawa. 